\title{
Loss of skeletal muscle mass affects the incidence of minimal hepatic encephalopathy: a case control study
}

\author{
Masakuni Tateyama ${ }^{1}$, Hideaki Naoe ${ }^{1}$, Motohiko Tanaka ${ }^{\text {* }}$, Kentaro Tanaka' , Satoshi Narahara', \\ Takayuki Tokunaga' , Takeshi Kawasaki', Yoko Yoshimaru', Katsuya Nagaoka', Takehisa Watanabe', \\ Hiroko Setoyama ${ }^{1,2}$, Yutaka Sasaki ${ }^{1,3}$ and Yasuhito Tanaka ${ }^{1}$
}

\begin{abstract}
Background: Sarcopenia is a syndrome characterized by progressive and systemic decreases in skeletal muscle mass and muscle strength. The influence or prognosis of various liver diseases in this condition have been widely investigated, but little is known about whether sarcopenia and/or muscle mass loss are related to minimal hepatic encephalopathy (MHE).

Methods: To clarify the relationship between MHE and sarcopenia and/or muscle mass loss in patients with liver cirrhosis.

Methods: Ninety-nine patients with liver cirrhosis were enrolled. MHE was diagnosed by a neuropsychiatric test. Skeletal mass index (SMI) and Psoas muscle index (PMI) were calculated by dividing skeletal muscle area and psoas muscle area at the third lumbar vertebra by the square of height in meters, respectively, to evaluate muscle volume.

Results: This study enrolled 99 patients (61 males, 38 females). MHE was detected in 48 cases (48.5\%) and sarcopenia in 6 cases (6.1\%). Patients were divided into two groups, with or without MHE. Comparing groups, no significant differences were seen in serum ammonia concentration or rate of sarcopenia. SMI was smaller in patients with MHE (46.4 $\left.\mathrm{cm}^{2} / \mathrm{m}^{2}\right)$ than in those without $\left(51.2 \mathrm{~cm}^{2} / \mathrm{m}^{2}, P=0.027\right)$. Similarly, PMI was smaller in patients with MHE $\left(4.24 \mathrm{~cm}^{2} /\right.$ $\left.\mathrm{m}^{2}\right)$ than in those without $\left(5.53 \mathrm{~cm}^{2} / \mathrm{m}^{2}, P=0.003\right)$. Skeletal muscle volume, which is represented by $\mathrm{SMI}$ or PMI was a predictive factor related to $\mathrm{MHE}\left(\mathrm{SMI} \geq 50 \mathrm{~cm}^{2} / \mathrm{m}^{2}\right.$; odds ratio $0.300, P=0.002, \mathrm{PMI} \geq 4.3 \mathrm{~cm}^{2} / \mathrm{m}^{2}$; odds ratio 0.192 , $P=0.001)$.
\end{abstract}

Conclusions: Muscle mass loss was related to minimal hepatic encephalopathy, although sarcopenia was not. Measurement of muscle mass loss might be useful to predict MHE.

Keywords: Minimal hepatic encephalopathy, Skeletal muscle index, Liver cirrhosis, Sarcopenia

*Correspondence: mtanaka03@kumamoto-u.ac.jp

1 Department of Gastroenterology and Hepatology, Graduate School of Medical Sciences, Kumamoto University, Honjo 1-1-1, Chuo-ku, Kumamoto 860-8556, Japan

Full list of author information is available at the end of the article

\section{Background}

Hepatic encephalopathy (HE) is a complication of liver cirrhosis, and reduces quality of life (QOL) for the patient. Minimal HE (MHE) is a neuropsychiatric abnormality without clinical overt symptoms of $\mathrm{HE}$ [1-3], and is diagnosed using sensitive neuropsychological and neurophysiological examinations. Difficulty in diagnosing MHE aggravates not only QOL, but also 
prognosis for patients [4-6]. To improve these outcomes, early detection of MHE is needed.

Ammonia is a typical molecule inducing encephalopathy. In cirrhotic patients, ammonia metabolism is attenuated in the liver. On the other hand, muscle plays an important role in ammonia decomposition. Loss of muscle mass would thus presumably induce deteriorations in ammonia metabolism. In addition, ammonia itself reportedly inhibits protein synthesis in muscle. Sarcopenia is thus an unfavorable condition in terms of ammonia metabolism, since it involves losses of both mass and strength in skeletal muscle. Furthermore, sarcopenia affects clinical outcomes in various liver diseases [7]. The frequency of sarcopenia increases with the progression of liver disease.

Although HE is associated with sarcopenia and muscle mass loss, whether MHE is associated with sarcopenia and/or muscle mass loss remains unclear. The purpose of this study was to clarify the relationship between MHE and sarcopenia and muscle mass loss in patients with liver cirrhosis.

\section{Methods}

\section{Study cohort}

Patients with cirrhosis were enrolled from May 2017 to December 2018 in Kumamoto University Hospital. Clinical records, laboratory data and clinical imaging findings were collected at the time of entry. Patients with cirrhosis were diagnosed by clinical findings and/ or pathological results. Exclusion criteria were as follows: (1) history of overt HE; (2) patients with cognitive impairment (e.g., Alzheimer disease); (3) presence of advanced Hepatocellular carcinoma (HCC) on admission (although HCC patients who met Milan criteria were not excluded: single tumor $<5 \mathrm{~cm}$ in maximum diameter or $\leq 3$ tumors, all $<3 \mathrm{~cm}$ in diameter [8]); or (4) use of psychiatric drugs (e.g., anti-Parkinson's disease agents, antipsychotics, or antidepressants) or narcotics.

\section{Testing for MHE}

To diagnose MHE, we used the neuropsychiatric-test (NP-test) application on a tablet computer (iPad; Apple, USA). This application was provided by Otsuka Pharmaceutical Co. Ltd. (Japan) on the site of the Japan Society of Hepatology. We used the following four tests: number connection test (NCT)-A; NCT-B; the digit symbol test; and the block design test. This application includes these tests to diagnose MHE. If abnormal results are obtained on two or more of these tests, the patient was diagnosed with MHE [1].

\section{Judgement of sarcopenia}

To diagnose sarcopenia, we used the criteria for sarcopenia proposed by the Japan Society of Hepatology [7]. The criteria comprise grip strength and muscle mass. Grip strength was measured using a Smedley-type dynamometer and the mean of two measurements for both sides was used as the measured value. Skeletal muscle area was determined on $\mathrm{CT}$ at the level of the third lumbar vertebra (L3) on a slice showing both transverse processes and was measured by manual tracing using the SYNAPSE VINCENT 3D image analysis system (Fujifilm, Japan) (Fig. 1). Simultaneously, the area of both left and right iliopsoas muscle was measured by manual tracing as psoas muscle area. Skeletal muscle index (SMI) was calculated as follow: skeletal muscle area at the L3 level was divided by the square of height in meters (muscle mass area $\left[\mathrm{cm}^{2}\right] /$ height $\left.{ }^{2}\left[\mathrm{~m}^{2}\right]\right)$. Likewise, psoas muscle index (PMI) was calculated by dividing psoas muscle area at the L3 level by the square of height in meters (muscle mass area $\left[\mathrm{cm}^{2}\right] /$ height $\left.{ }^{2}\left[\mathrm{~m}^{2}\right]\right)$ [9]. Cut-off values for grip strength (26 kg in men, $18 \mathrm{~kg}$ in women) and SMI $\left(42 \mathrm{~cm}^{2} / \mathrm{m}^{2}\right.$ in men; $38 \mathrm{~cm}^{2} / \mathrm{m}^{2}$ in women) were based on the guidelines for sarcopenia in liver disease issued by the Japan Society of Hepatology [7]. If the patient showed values below cut-off levels in both grip strength and SMI, sarcopenia was diagnosed. We also determined muscle strength loss if the value was below the cut-off level for grip strength, and muscle mass loss if the value was below the cut-off level for skeletal muscle index according to sex.

\section{Statistical analysis}

To explore differences between groups, Student's t test or the non-parametric test was used for continuous

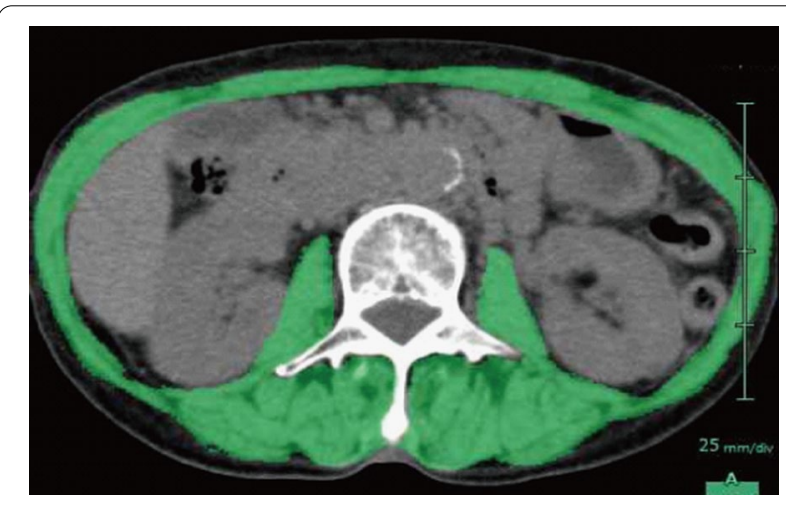

Fig. 1 Representative of CT scan image. After skeletal muscle area was estimated by subtracting the areas of visceral fat and subcutaneous fat from the total area, it was determined on CT by manual tracing (green area). The areas of visceral and subcutaneous fat were calculated by the abdominal application software, automatically 
variables, and the chi-squared test was used for categorical variables. Continuous variables are expressed as median (range) and categorical variables as number (percentage). Continuous variables were dichotomized with respect to the median value or clinically meaningful values validated by receiver operating characteristic analysis in logistic regression analyses. The cut-off values of these variables, calculated by CT image such as SMI, were determined by ROC curve and youden index. Logistic regression analysis was performed to examine predictors of MHE. Values of $P<0.05$ were considered statistically significant. Data analysis was performed using SPSS version 22 statistical software (IBM SPSS Japan, Tokyo, Japan).

\section{Results}

\section{Patient characteristics}

Background characteristics of patients are shown in Table 1.Of the 99 patients, median age was 70.0 years old and 61 patients $(61.6 \%)$ were men. Etiology was hepatitis $B$ virus (HBV) in 18 patients, hepatitis $\mathrm{C}$ virus (HCV) in 52 patients, and neither $\mathrm{HBV}$ nor $\mathrm{HCV}$ in 29 patients. Thirty HCV-infected patients achieved SVR among 52 patients. Among all patients, 29 (29.3\%) did not have HCC, while 58 (58.6\%) showed complications of gastroesophageal varices. Sixty patients were classified as ChildPugh class A. For all patients, median grip strength was $24.6 \mathrm{~kg}$ and median SMI was $47.9 \mathrm{~cm}^{2} / \mathrm{m}^{2}$.

\section{Difference between presence or absence of MHE}

Table 2 shows a comparison of patient background characteristics between patients with and without MHE. Forty-eight patients were judged as positive for MHE. Body weight was lower in patients with MHE than in those without MHE. Concentrations of ammonia were similar between groups. In amino acid analysis (concentration of branched-chain amino acids (BCAA), that of Tyrosine and molar ratio of BCAA to tyrosine (BTR)), no differences were evident between groups. On the other hand, grip strength, body height, body weight, body mass index (BMI), skeletal muscle area at the L3 level, SMI, psoas muscle area and PMI differed significantly between groups. Median SMI in patients with and without MHE were $46.4 \mathrm{~cm}^{2} / \mathrm{m}^{2}$ and $51.2 \mathrm{~cm}^{2} / \mathrm{m}^{2}$, respectively.

\section{Sarcopenia and muscle mass loss}

In this cohort, 6 patients $(6.7 \%)$ were diagnosed with sarcopenia. Figure 2 shows the incidence of MHE stratified by the presence of sarcopenia. Incidence of MHE in patients with and without sarcopenia was $50.0 \%$ and $48.4 \%$, respectively (Fig. 2a). No significant difference in the incidence of MHE was evident regardless of muscle strength loss or muscle mass loss (Fig. 2b). However,
Table 1 Patient background characteristics $(n=99)$

\begin{tabular}{|c|c|}
\hline Age (years) & $70.0(42-90)$ \\
\hline Male, n (\%) & $61(61.6)$ \\
\hline \multicolumn{2}{|l|}{ Etiology } \\
\hline HBV, n (\%) & $18(18.2)$ \\
\hline HCV (including SVR), n (\%) & $52(52.5)$ \\
\hline NBNC, n (\%) & $29(29.3)$ \\
\hline Taking BCAA, n (\%) & $28(28.3)$ \\
\hline Taking diuretic, n (\%) & $25(25.3)$ \\
\hline Alcohol, n (\%) & $39(39.4)$ \\
\hline Diabetes, n (\%) & $33(33.3)$ \\
\hline HCC, n (\%) & $70(70.7)$ \\
\hline Esophageal or gastric varices, n (\%) & $40(40.4)$ \\
\hline Porto-systemic shunts, n (\%) & $35(35)$ \\
\hline Ascites, n (\%) & $10(10.1)$ \\
\hline \multicolumn{2}{|l|}{ Child-Pugh Class } \\
\hline A & $60(60.6)$ \\
\hline B & $25(25.3)$ \\
\hline C & $4(4.0)$ \\
\hline Sarcopenia, n (\%) & $6(6.1)$ \\
\hline Body height (m) & $1.59(1.37-1.90)$ \\
\hline Body weight (kg) & $57.4(36.6-92.8)$ \\
\hline $\mathrm{BMI}\left(\mathrm{kg} / \mathrm{m}^{2}\right)$ & $23.7(16.0-33.9)$ \\
\hline Grip strength (kg) & $24.6(7.2-43.5)$ \\
\hline Hemoglobin (g/L) & $128(79-169)$ \\
\hline Platelets $\left(\times 10^{3} / \mu \mathrm{L}\right)$ & $107(21-390)$ \\
\hline $\operatorname{ALT}(U / L)$ & $23(8-123)$ \\
\hline Y-GTP (U/L) & $41(13-696)$ \\
\hline Cholinesterase (U/L) & $206(53-379)$ \\
\hline Albumin (g/L) & $38(22-49)$ \\
\hline Total cholesterol (mmol/L) & $4.16(2.20-6.59)$ \\
\hline Ammonia (mol/L) & $31.1(4.11-157.37)$ \\
\hline Prothrombin time (\%) & $80(31-115)$ \\
\hline Sodium (mEq/L) & $140(133-146)$ \\
\hline $\mathrm{BCAA}(\mathrm{mmol} / \mathrm{L})$ & $423.7(228.3-1459.9)$ \\
\hline Tyrosine (mmol/L) & $96.2(37.1-174.0)$ \\
\hline BTR & $4.75(1.44-11.07)$ \\
\hline Subcutaneous fat area $\left(\mathrm{cm}^{2}\right)$ & $101.61(3.84-332.49)$ \\
\hline Visceral fat area $\left(\mathrm{cm}^{2}\right)$ & $111.37(7.03-287.84)$ \\
\hline CT level of skeletal muscles (HU) & $22.70(-16.42-47.52)$ \\
\hline Skeletal muscle area $\left(\mathrm{cm}^{2}\right)$ & $118.74(72.12-188.46)$ \\
\hline Skeletal muscle index $\left(\mathrm{cm}^{2} / \mathrm{m}^{2}\right)$ & $47.9(29.4-68.5)$ \\
\hline Psoas muscle area $\left(\mathrm{cm}^{2}\right)$ & $12.47(5.11-24.49)$ \\
\hline Psoas muscle index $\left(\mathrm{cm}^{2} / \mathrm{m}^{2}\right)$ & $5.02(2.45-9.20)$ \\
\hline
\end{tabular}

Continuous variables are expressed as medians. Numbers in parentheses of continuous variables show each range of variables

$H B V$, hepatitis $B$ virus; $H C V$, hepatitis $C$ virus; $N B N C$, non-B, non-C etiology; $H C C$, hepatocellular carcinoma; BMI, body mass index; ALT, alanine aminotransferase; $\gamma$-GTP, $\gamma$-glutamyl transpeptidase; CRP, C-reactive protein; BCAA, branched-chain amino acids; BTR, molar ratio of branched-chain amino acids to tyrosine; $C T$, computed tomography 
Table 2 Comparison of patient background characteristics between presence or absence of minimal hepatic encephalopathy

\begin{tabular}{|c|c|c|c|}
\hline & MHE $(-)(n=51)$ & $\operatorname{MHE}(+)(n=48)$ & $P$ value \\
\hline Age (years) & 72 & 68 & 0.944 \\
\hline Male, n (\%) & $34(66.7)$ & $27(56.3)$ & 0.287 \\
\hline Etiology & & & 0.677 \\
\hline HBV, n (\%) & $11(21.6)$ & $7(14.6)$ & \\
\hline HCV (include SVR), n (\%) & $24(47.0)$ & $28(58.3)$ & \\
\hline NBNC, n (\%) & $16(31.4)$ & $13(27.1)$ & \\
\hline Taking BCAA, n (\%) & $11(21.6)$ & $17(35.4)$ & 0.126 \\
\hline Taking diuretic, n (\%) & $12(23.5)$ & $13(27.1)$ & 0.684 \\
\hline Alcohol, n (\%) & $22(43.1)$ & $17(35.4)$ & 0.432 \\
\hline Diabetes, n (\%) & $17(33.3)$ & $16(33.3)$ & 1.000 \\
\hline $\mathrm{HCC}, \mathrm{n}(\%)$ & $36(70.6)$ & $34(75.0)$ & 0.979 \\
\hline Esophageal or gastric varices, n (\%) & $19(38.0)$ & $21(43.8)$ & 0.563 \\
\hline Porto-systemic shunts, n (\%) & $22(43.1)$ & $13(27.1)$ & 0.095 \\
\hline Ascites, n (\%) & $4(7.8)$ & $6(12.5)$ & 0.332 \\
\hline Child-Pugh Class & & & 0.879 \\
\hline A & $30(66.7)$ & $30(68.4)$ & \\
\hline$B$ or $C$ & $15(33.3)$ & $14(31.8)$ & \\
\hline Sarcopenia, n (\%) & $3(5.9)$ & $3(6.3)$ & 0.632 \\
\hline Body height (m) & 1.61 & 1.56 & 0.023 \\
\hline Body weight (kg) & 60.8 & 53.9 & 0.002 \\
\hline $\mathrm{BMI}\left(\mathrm{kg} / \mathrm{m}^{2}\right)$ & 24.52 & 22.66 & 0.021 \\
\hline Grip strength (kg) & 28.3 & 21.9 & 0.041 \\
\hline Hemoglobin (g/L) & 133 & 124 & 0.181 \\
\hline Platelet $\left(\times 10^{3} / \mu \mathrm{L}\right)$ & 107 & 106.5 & 0.563 \\
\hline $\mathrm{ALT}(\mathrm{U} / \mathrm{L})$ & 26 & 23 & 0.385 \\
\hline Y-GTP (U/L) & 43 & 39 & 0.975 \\
\hline Cholinesterase (U/L) & 210 & 203 & 0.416 \\
\hline Albumin (g/L) & 39 & 38 & 0.863 \\
\hline Total cholesterol (mmol/L) & 4.16 & 4.16 & 0.991 \\
\hline Ammonia ( $\mu \mathrm{mol} / \mathrm{L})$ & 31.1 & 30.5 & 0.674 \\
\hline Prothrombin time (\%) & 79.0 & 81.5 & 0.483 \\
\hline Sodium (mEq/L) & 140 & 139.5 & 0.946 \\
\hline BCAA (mmol/L) & 465.9 & 404.0 & 0.093 \\
\hline Tyrosine (mmol/L) & 99.5 & 91.1 & 0.076 \\
\hline BTR & 4.62 & 4.78 & 0.978 \\
\hline Subcutaneous fat area $\left(\mathrm{cm}^{2}\right)$ & 119.99 & 97.35 & 0.198 \\
\hline Visceral fat area $\left(\mathrm{cm}^{2}\right)$ & 111.37 & 111.09 & 0.385 \\
\hline $\mathrm{CT}$ level of skeletal muscle (HU) & 23.46 & 22.51 & 0.287 \\
\hline Skeletal muscle area $\left(\mathrm{cm}^{2}\right)$ & 125.85 & 108.23 & 0.003 \\
\hline Skeletal muscle index $\left(\mathrm{cm}^{2} / \mathrm{m}^{2}\right)$ & 51.22 & 46.40 & 0.027 \\
\hline Psoas muscle area $\left(\mathrm{cm}^{2}\right)$ & 14.34 & 10.85 & 0.002 \\
\hline Psoas muscle index $\left(\mathrm{cm}^{2} / \mathrm{m}^{2}\right)$ & 5.53 & 4.24 & 0.003 \\
\hline
\end{tabular}

Continuous variables are expressed as medians

SMI, skeletal muscle index; PMI, psoas muscle index 

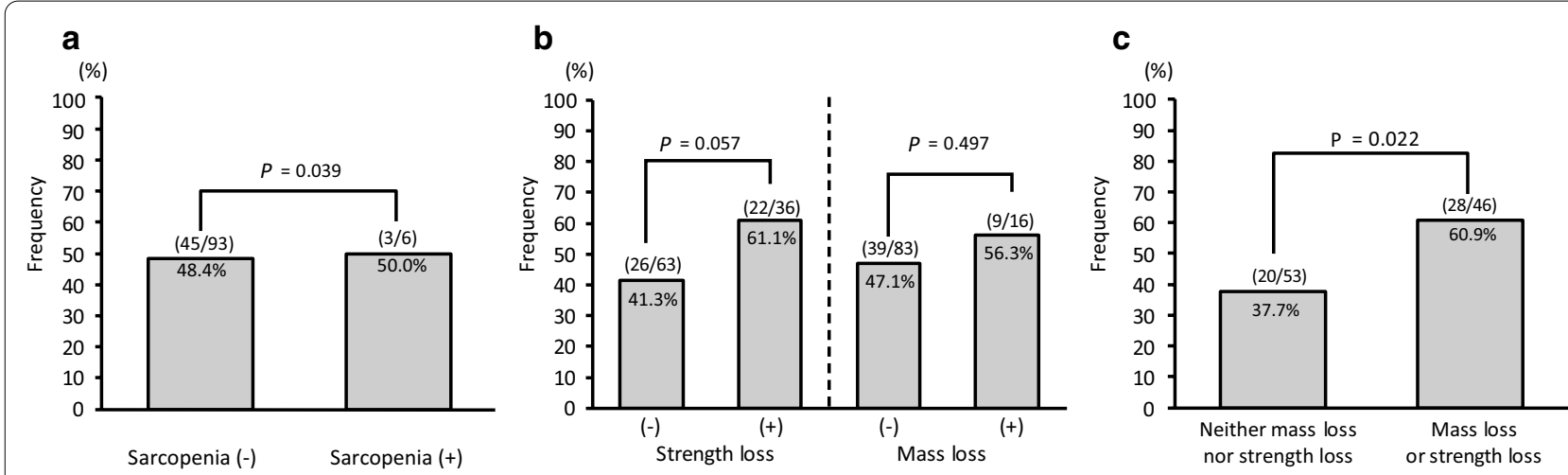

Fig. 2 Incidence of MHE with and without sarcopenia (a), muscle strength loss or mass loss (b, c). In cases with strength loss or volume loss, the incidence of MHE was similar (b). But, incidence of MHE in patients with volume loss or strength loss was significantly higher than that in patients with neither volume loss nor strength loss (c)

we found that presence of either muscle mass loss or strength loss was significantly associated with higher incidence of MHE, whereas absence of either was not (Fig. 2c).

\section{Predictive factors for incidence of MHE}

Next, we performed univariate analysis to elucidate factors associated with MHE using all variables in Table 2. Cut-off values of SMI and PMI defined by ROC curve were $50 \mathrm{~cm}^{2} / \mathrm{m}^{2}$ and $4.3 \mathrm{~cm}^{2} / \mathrm{m}^{2}$, respectively. Table 3 showed only the variables with statistically significant differences except for those that were not significantly different by univariate analysis. Body weight, BMI, concentration of BCAA, skeletal muscle area, SMI, psoas muscle area and PMI were significantly correlated with the presence of MHE (Table 3), whereas sarcopenia was not significantly associated with MHE. Since BMI and SMI include body weight and skeletal muscle area, respectively, we focused on BMI, concentration of BCAA and SMI, and performed multivariate analysis using these. As a result, SMI was detected as the only significant factor $\left(\geq 50 \mathrm{~cm}^{2} / \mathrm{m}^{2}\right.$, odds ratio (OR) 0.300 , $P=0.006)$. Similarly, when using PMI instead of SMI, PMI was detected as the only significant factor $(\geq 4.3$ $\mathrm{cm}^{2} / \mathrm{m}^{2}$, odds ratio (OR) 0.192, $P=0.001$ ) (Table 3). The incidence rate of MHE was $59.6 \%$ in patients with $\mathrm{SMI}<50 \mathrm{~cm}^{2} / \mathrm{m}^{2}$, and $33.3 \%$ in patients with $\mathrm{SMI} \geq 50$ $\mathrm{cm}^{2} / \mathrm{m}^{2}$ and that was $71.4 \%$ in patients with $\mathrm{PMI}<4.3$ $\mathrm{cm}^{2} / \mathrm{m}^{2}$, and $35.9 \%$ in patients with $\mathrm{PMI} \geq 4.3 \mathrm{~cm}^{2} / \mathrm{m}^{2}$, respectively (Fig. 3). In addition, the all six patients with sarcopenia belonged to the low BMI group, which was less than $24 \mathrm{~kg} / \mathrm{m}^{2}$.

\section{Incidence of MHE classified by sex and age}

Since SMI varies among sex, we examined SMI and the incidence of MHE by sex. Median SMI was $51.0 \mathrm{~cm}^{2} / \mathrm{m}^{2}$ in males and $45.1 \mathrm{~cm}^{2} / \mathrm{m}^{2}$ in females (Table 4). The incidence of MHE was higher in the group with SMI below the cut-off level than in the group with SMI above the cut-off in both males and females (Fig. 4a). Regarding the frequency of MHE, there was a similar tendency in PMI (Fig. 4b). Next, patients with high age showed the possibility of declines in higher brain functions such as recognition and decision making. We also examined the incidence of MHE by age. Table 4 shows median SMI classified by the age threshold of 80 years old. While grip strength differed between subjects under or over 80 years old, SMI and PMI were similar between groups. The incidence of MHE differed significantly between groups classified using the SMI or PMI level below and above the cut-off level in patients $<80$ years old (Fig. $4 \mathrm{c}$, d).

\section{Discussion}

This study showed that MHE was affected by skeletal muscle mass and suggests that skeletal muscle may play an important role in MHE. As a neuropsychiatric abnormality without overt clinical symptoms of HE [1-3], MHE is considered to be the primary status of overt HE [10]. MHE leads to deteriorations in QOL $[4,5]$ and impairment of driving skill for motor vehicles [11-17]. Moreover, MHE is associated with falls [18, 19], learning impairment [20] and poor prognosis [6, 19, 21]. In addition, MHE is reportedly related to the survival of patients with liver cirrhosis [6, 22]. Early detection of patients with MHE is therefore necessary.

In patients with cirrhosis, ammonia, as the main substance causing HE, is increased in serum, since its metabolism is attenuated in the liver. Ammonia metabolism by skeletal muscle can compensate for impaired hepatic metabolism [23-25]. Moreover, loss of skeletal muscle readily occurs in patients with cirrhosis due to alterations in protein turnover, energy disposal or metabolism [26]. 
Table 3 Predictive factors for the presence of minimal hepatic encephalopathy

\begin{tabular}{|c|c|c|c|}
\hline & & \multicolumn{2}{|l|}{ Univariate } \\
\hline & & Odds ratio & $P$ value \\
\hline \multicolumn{4}{|c|}{ Body weight, kg } \\
\hline \multicolumn{2}{|c|}{$<60$} & 1 & \\
\hline$\geq 60$ & & 0.357 & 0.016 \\
\hline \multicolumn{4}{|c|}{$\mathrm{BMI}, \mathrm{kg} / \mathrm{m}^{2}$} \\
\hline \multicolumn{2}{|c|}{$\geq 24$} & 1 & \\
\hline$\geq 24$ & & 0.318 & 0.007 \\
\hline \multicolumn{4}{|c|}{$\mathrm{BCAA}, \mu \mathrm{mol} / \mathrm{L}$} \\
\hline \multicolumn{2}{|c|}{$<450$} & 1 & \\
\hline \multirow{2}{*}{\multicolumn{2}{|c|}{$\begin{array}{l}\geq 450 \\
\text { Skeletal muscle area } \mathrm{cm}^{2}\end{array}$}} & 0.355 & 0.018 \\
\hline & \multicolumn{3}{|c|}{ Skeletal muscle area, $\mathrm{cm}^{2}$} \\
\hline \multicolumn{2}{|c|}{$<120$} & 1 & \\
\hline \multicolumn{2}{|l|}{$\geq 120$} & 0.297 & 0.004 \\
\hline \multicolumn{4}{|c|}{ Skeletal muscle index, $\mathrm{cm}^{2} / \mathrm{m}^{2}$} \\
\hline \multicolumn{2}{|c|}{$<50$} & 1 & \\
\hline \multicolumn{2}{|c|}{$\geq 50$} & 0.338 & 0.011 \\
\hline \multicolumn{4}{|c|}{ Psoas muscle area, $\mathrm{cm}^{2}$} \\
\hline \multicolumn{2}{|c|}{$<9.5$} & 1 & \\
\hline$\geq 9.5$ & & 0.205 & 0.002 \\
\hline Psoas $\mathrm{m}$ & & & \\
\hline$<4.3$ & & 1 & \\
\hline$\geq 4.3$ & & 0.224 & 0.001 \\
\hline & Multivariate & & \\
\hline & Odds ratio & $P$ value & $95 \% \mathrm{Cl}$ \\
\hline BMI, kg/ & & & \\
\hline$<24$ & & & \\
\hline$\geq 24$ & & & \\
\hline$B C A A, \mu$ & & & \\
\hline$<450$ & & & \\
\hline$\geq 450$ & & & \\
\hline Skeletal & & & \\
\hline$<50$ & & & \\
\hline$\geq 50$ & 0.300 & 0.006 & $0.126-0.712$ \\
\hline & Multivariate & & \\
\hline & Odds ratio & $P$ value & $95 \% \mathrm{Cl}$ \\
\hline BMl, kg/ & & & \\
\hline$<24$ & & & \\
\hline$\geq 24$ & & & \\
\hline$B C A A, \mu$ & & & \\
\hline$<450$ & & & \\
\hline$\geq 450$ & & & \\
\hline Psoas m & & & \\
\hline$<4.3$ & & & \\
\hline$\geq 4.3$ & 0.192 & 0.001 & $0.075-0.491$ \\
\hline
\end{tabular}

$\mathrm{Cl}$, confidence interval 

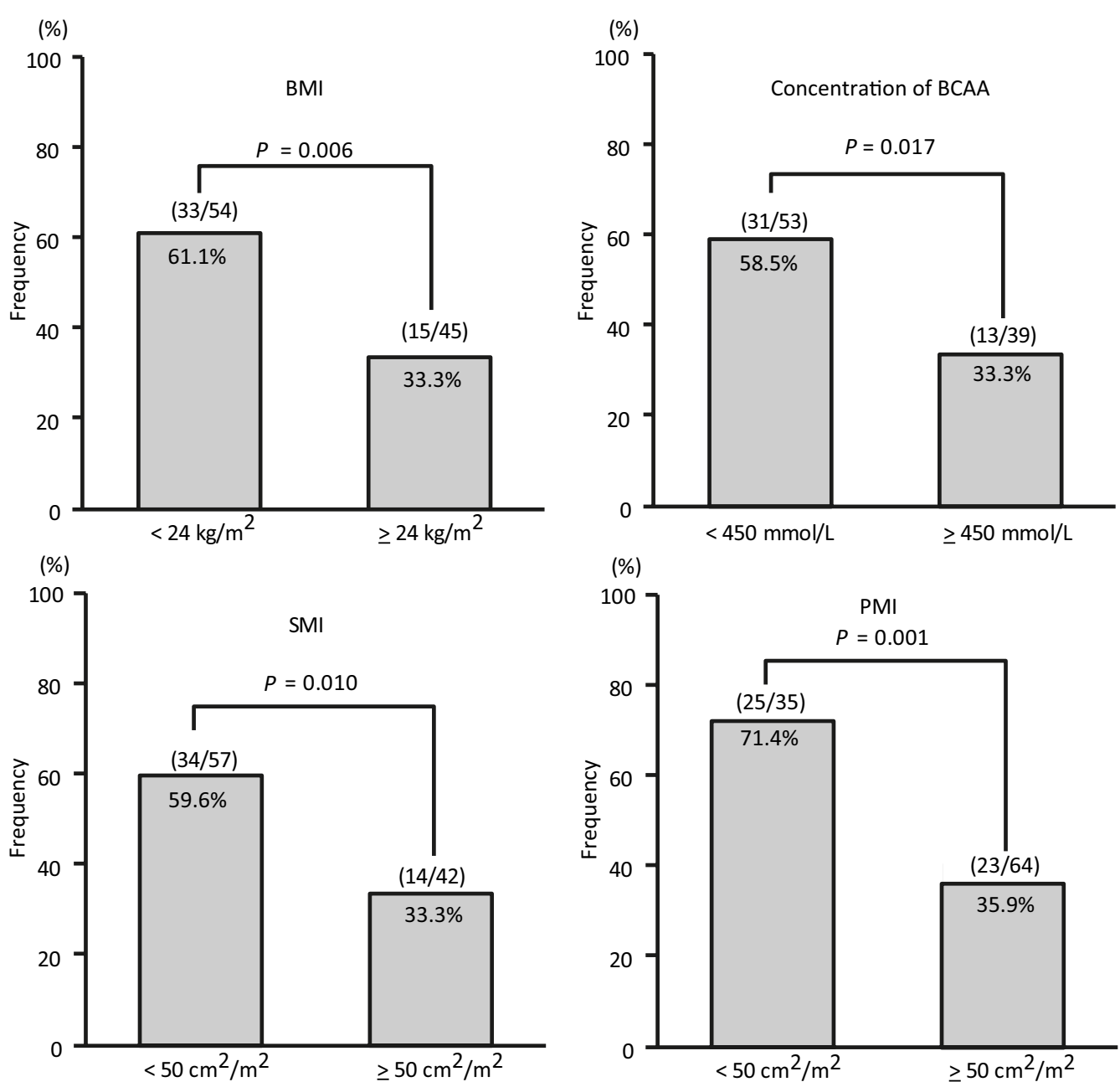

Fig. 3 Incidence of MHE by BMI, BCAA concentration, SMI and PMI. Incidence of minimal hepatic encephalopathy was significantly higher in cases below each cut-off level than in cases above each cut-off

Table 4 SMI and PMI by sex and age

\begin{tabular}{|c|c|c|c|}
\hline & Male $(n=61)$ & Female $(n=38)$ & $P$ value \\
\hline \multicolumn{4}{|l|}{ (A) SMI and PMI by sex } \\
\hline Grip strength $(\mathrm{kg})$ & $30.9(14.2-43.5)$ & $17.6(7.2-25.2)$ & $<0.001$ \\
\hline Skeletal muscle area $\left(\mathrm{cm}^{2}\right)$ & $131.90(86.99-188.46)$ & $98.32(72.12-143.99)$ & $<0.001$ \\
\hline Skeletal muscle index $\left(\mathrm{cm}^{2} / \mathrm{m}^{2}\right)$ & $51.0(29.4-68.5)$ & $45.1(32.5-65.0)$ & 0.001 \\
\hline Psoas muscle area $\left(\mathrm{cm}^{2}\right)$ & $14.88(6.46-24.49)$ & $8.89(5.11-15.79)$ & $<0.001$ \\
\hline \multirow[t]{2}{*}{ Psoas muscle index $\left(\mathrm{cm}^{2} / \mathrm{m}^{2}\right)$} & $5.6(3.1-9.2)$ & $4.0(2.5-7.6)$ & $<0.001$ \\
\hline & $<80$ years $(n=84)$ & $\geq 80$ years $(n=15)$ & $P$ value \\
\hline \multicolumn{4}{|l|}{ (B) SMI and PMI by age } \\
\hline Grip strength $(\mathrm{kg})$ & $26.8(8.9-43.5)$ & $17.0(7.2-28.3)$ & $<0.001$ \\
\hline Skeletal muscle area $\left(\mathrm{cm}^{2}\right)$ & $122.01(72.12-188.46)$ & $99.59(72.31-173.66)$ & 0.023 \\
\hline Skeletal muscle index $\left(\mathrm{cm}^{2} / \mathrm{m}^{2}\right)$ & $47.9(29.4-68.5)$ & $47.3(32.5-66.7)$ & 0.507 \\
\hline Psoas muscle area $\left(\mathrm{cm}^{2}\right)$ & $13.19(5.11-24.49)$ & $9.00(5.33-23.29)$ & 0.028 \\
\hline Psoas muscle index $\left(\mathrm{cm}^{2} / \mathrm{m}^{2}\right)$ & $5.2(2.5-9.2)$ & $4.1(2.5-8.9)$ & 0.212 \\
\hline
\end{tabular}

SMI, Skeletal muscle index; PMI, Psoas muscle index 

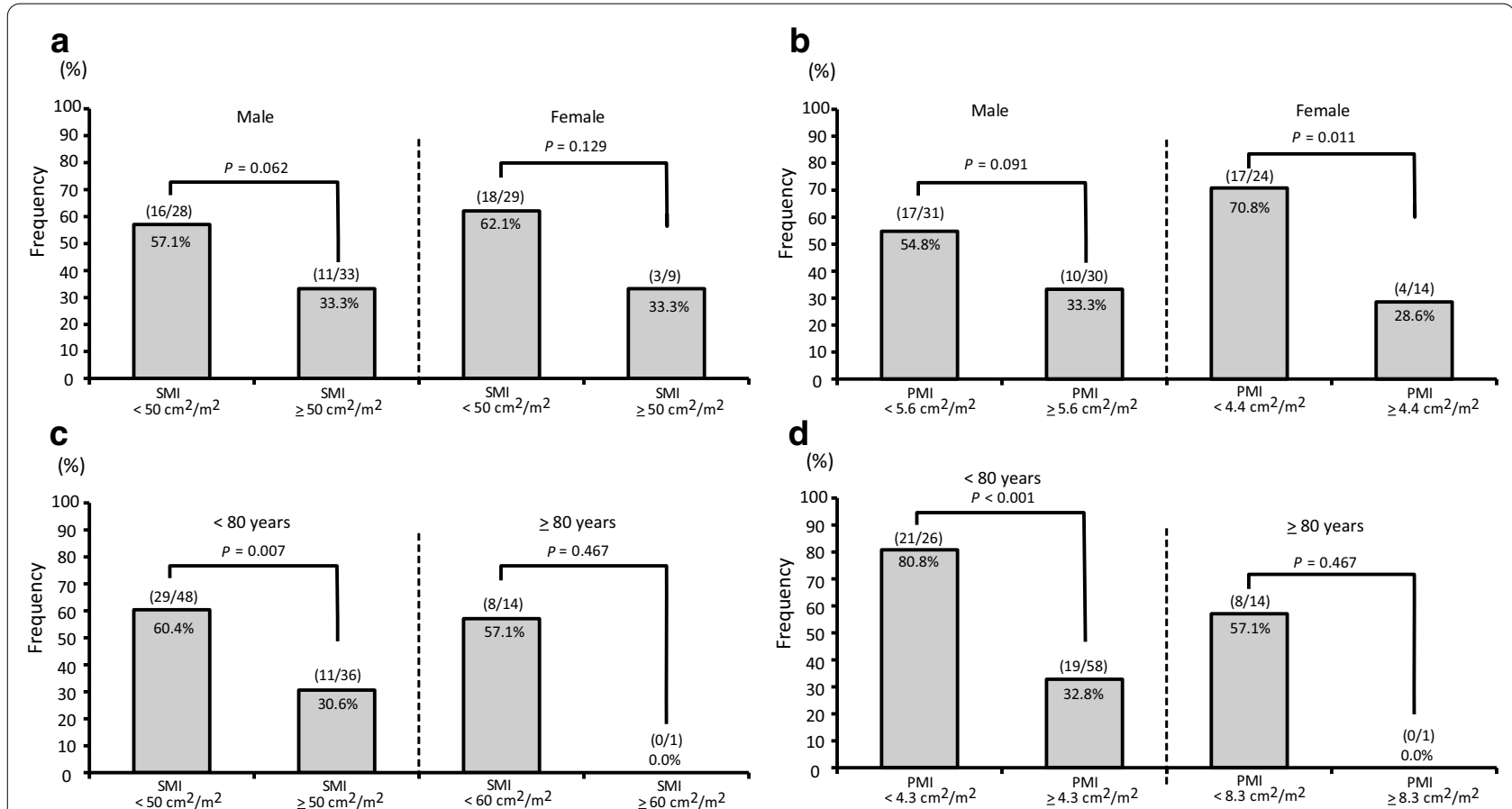

Fig. 4 Incidence of minimal MHE by sex $(\mathbf{a}, \mathbf{b})$ and age $(\mathbf{c}, \mathbf{d})$. In cases with lower SMI or PMI, incidence of minimal hepatic encephalopathy tended to be higher than in cases above the cut-off, although the difference was not significant $(\mathbf{a}, \mathbf{b})$. In patients less than 80 years old, incidence of minimal hepatic encephalopathy was significantly higher in cases with lower SMI or PMI than in cases with them above the cut-off. In patients more than 80 years old, no difference was seen between below and above the cut-off (c, d)

Generally, skeletal muscle loss exacerbates deficiencies in detoxification of ammonia, inducing HE. Qureshi et al. reported that ammonia level correlates with the severity of HE [27]. Although the concentration of ammonia in our study showed no significant difference between patients with or without MHE, loss of skeletal muscle mass may affect the presence of MHE in patients with liver cirrhosis. In addition, Qiu et al. reported that hyperammonemia led to inhibition of protein synthesis through the increase in myostatin mediated by nuclear factor- $\mathrm{k} B$ [28]. These findings suggest that hyperammonemia and skeletal muscle loss might affect each other in a bi-directional manner.

Sarcopenia or muscle loss is considered a predictor of impaired QOL [29], postoperative major complication [30], prognosis [31-34] and physical disability [35]. Since advanced-stage HCC influences nutritional status, we excluded patients with HCC who did not meet Milan criteria [8] from the present study. Hanai et al. described sarcopenia as a predictor of MHE [36]. Moreover, several reports have shown that sarcopenia or muscle depletion affects the risk of overt HE or MHE [37-39]. These reports potentially support our result regarding patients without advanced HCC. According to the guidelines for sarcopenia in liver disease issued by the Japan Society of Hepatology, the proportion of sarcopenia in patients with cirrhosis varies within the range of 10-70\% [7]. Because too few patients with sarcopenia were enrolled in our study, sarcopenia might not have been detected as a predictor of MHE. The exclusion criteria for advanced HCC in our study might have caused the discrepancy between our study and previous reports [36, 37]. With regards to cirrhotic patients without HCC or with HCC within Milan criteria, although the incidence of sarcopenia was quite low, we could predict the incidence of MHE in terms of muscle mass loss. We showed that PMI, as well as SMI were related to the presence of MHE. Since the measurement of psoas muscle area is easier than that of skeletal muscle area in the clinical setting, it can be also useful to check PMI as an indicator of muscle volume.

Skeletal muscle, SMI, skeletal muscle area and PMI were significant different between male and female. We examined the association between MHE and SMI or PMI separately for men and women, but the frequency of MHE was higher in the group with SMI or PMI below the cut-off level than in the group with them above it. This result may be due to a gender-independent relationship between muscle volume and MHE. Mild cognitive impairment (MCI) was not completely excluded because of the difficulty detecting this pathology in clinical settings. To remove this bias, we additionally analyzed the incidence of MHE among subjects under 80 years old, 
to reduce the possibility of MCI. The incidence of MHE differed significantly between cases below and above the cut-off level of SMI in patients under 80 years old.

Although various drugs have been given for patients with MHE [40-44] to decrease ammonia levels or improve mental status, drugs that are effective against MHE are unclear. We showed that the concentration of BCAA correlated with the presence of MHE, suggesting that administration of BCAA may be a reasonable treatment for MHE, because of its potential efficacy ameliorating skeletal muscle mass loss. Since current study was a case-control study, which fixed observation point, we were not able to evaluate whether the administration of BCAA would effect on MHE. Further study is needed to evaluate the curative or preventive effect of BCAA on MHE.

Several limitations to this study must be considered. First, the number of patients enrolled in this study was small. It may be too small to decide the appropriate cutoff level using ROC curve. Further analysis of a larger number of patients is needed to confirm the current findings and suitable cut-off value of SMI and PMI. Second, we used skeletal muscle area at the L3 level for the evaluation of muscle mass. Although this SMI was previously reported to correlate with SMI as calculated using bioelectrical impedance analysis (BIA) [7], we did not evaluate skeletal muscle mass by BIA. Third, we used the NP-test to diagnose MHE. The Psychometric Hepatic Encephalopathy Score (PHES), Inhibitory Control Test (ICT), electroencephalography, critical flicker frequency, and Stroop EncephAlapp are also available to diagnose MHE, and the combination of these tests is reportedly more useful than single tests $[2,45]$ Although we used NP-tests as a simple method in the clinical setting, how many and which types of tests are best and are most reliable for diagnosing MHE remains unclear.

\section{Conclusions}

In conclusion, the present findings suggest that muscle mass loss might serve as a predictive factor for MHE among patients with liver cirrhosis and without advanced HCC. The therapeutic strategy for muscle mass loss would contribute to preventing occurrence of MHE.

\footnotetext{
Abbreviations

HE: Hepatic encephalopathy; QOL: Quality of life; MHE: Minimal hepatic encephalopathy; HCC: Hepatocellular carcinoma; NP-test: The neuropsychiatric-test, NCT-A: number connection test-A; NCT-B: Number connection test-B; SMI: Skeletal muscle index; PMI: Psoas muscle index; HBV: Hepatitis B virus; HCV: Hepatitis C virus; BCAA: Branched-chain amino acids; BTR: Tyrosine and molar ratio of BCAA to tyrosine; BMI: Body mass index; $\mathrm{MCl}$ : Mild cognitive impairment; BIA: Bioelectrical impedance analysis; PHES: Psychometric Hepatic Encephalopathy Score; ICT: Inhibitory control test.
}

Acknowledgements

We Acknowledged that Maki Nomura supported to test for MHE

\section{Authors' contributions}

$[\mathrm{MT}] 1$ contributed to the study conception and design. KT, SN, TT, TK and YY performed the data collection.[MT]1 performed the statistical analysis and drafted the first version of the manuscript. HN, KN, TW, HS, [MT]2, YT, and YS revised the manuscript. All authors read and approved the final manuscript. [MT]1 is corresponding to Masakuni Tateyama and [MT]2 is corresponding to Motohiko Tanaka, respectively. All authors read and approved the final manuscript.

\section{Funding}

The authors declare no conflict of interest.

\section{Availability of data and materials}

The datasets used and/or analyzed during the current study are available from the corresponding author on reasonable request.

\section{Ethics approval and consent to participate}

The study was conducted with adherence to the declaration of Helsinki. The study protocol was approved by the institutional review board of Kumamoto University (Approval No. 2238). Informed consent to participate this study was obtained from each patient in writing.

\section{Consent for publication}

Not applicable.

\section{Competing interests}

The authors declare no competing interests to this study.

\section{Author details \\ ${ }^{1}$ Department of Gastroenterology and Hepatology, Graduate School of Medical Sciences, Kumamoto University, Honjo 1-1-1, Chuo-ku, Kumamoto 860-8556, Japan. ${ }^{2}$ Kumamoto Rosai Hospital, 1670 Takeharatyo, Yatsushiro City, Kumamoto, Japan. ${ }^{3}$ Department of Health and Nutrition, Nagasaki International University, 2825-7 Huis Ten Bosch Machi, Sasebo City, Nagasaki 859-3298, Japan.}

Received: 11 July 2020 Accepted: 14 October 2020

Published online: 09 November 2020

\section{References}

1. Ferenci P, Lockwood A, Mullen K, Tarter R, Weissenborn K, Blei AT. Hepatic encephalopathy-definition, nomenclature, diagnosis, and quantification: final report of the working party at the 11th World Congresses of Gastroenterology, Vienna, 1998. Hepatology. 2002;35(3):716-21.

2. Weissenborn K. Diagnosis of minimal hepatic encephalopathy. J Clin Exp Hepatol. 2015a;5(Suppl 1):S54-9.

3. Weissenborn K. Hepatic encephalopathy: definition, clinical grading and diagnostic principles. Drugs. 2019;79(Suppl 1):5-9.

4. Ridola L, Nardelli S, Gioia S, Riggio O. Quality of life in patients with minimal hepatic encephalopathy. World J Gastroenterol. 2018;24(48):5446-53.

5. Agrawal S, Umapathy S, Dhiman RK. Minimal hepatic encephalopathy impairs quality of life. J Clin Exp Hepatol. 2015;5(Suppl 1):S42-8.

6. Flud CR, Duarte-Rojo A. Prognostic implications of minimal/covert hepatic encephalopathy: large-scale validation cohort studies. J Clin Exp Hepatol. 2019;9(1):112-6.

7. Nishikawa H, Shiraki M, Hiramatsu A, Moriya K, Hino K, Nishiguchi S. Japan society of hepatology guidelines for sarcopenia in liver disease (1st edition): recommendation from the working group for creation of sarcopenia assessment criteria. Hepatol Res. 2016;46(10):951-63.

8. Mazzaferro V, Regalia E, Doci R, Andreola S, Pulvirenti A, Bozzetti F, Montalto F, Ammatuna M, Morabito A, Gennari L. Liver transplantation for the treatment of small hepatocellular carcinomas in patients with cirrhosis. N Engl J Med. 1996;334(11):693-9.

9. Hamaguchi Y, Kaido T, Okumura S, Kobayashi A, Hammad A, Tamai Y, Inagaki N, Uemoto S. Proposal for new diagnostic criteria for low skeletal 
muscle mass based on computed tomography imaging in Asian adults. Nutrition. 2016;32(11-12):1200-5.

10. Romero-Gomez M, Boza F, Garcia-Valdecasas MS, Garcia E, Aguilar-Reina J. Subclinical hepatic encephalopathy predicts the development of overt hepatic encephalopathy. Am J Gastroenterol. 2001;96(9):2718-23.

11. Bajaj JS, Saeian K, Schubert CM, Hafeezullah M, Franco J, Varma RR, Gibson DP, Hoffmann RG, Stravitz RT, Heuman DM, et al. Minimal hepatic encephalopathy is associated with motor vehicle crashes: the reality beyond the driving test. Hepatology. 2009;50(4):1175-83.

12. Shaw J, Bajaj JS. Covert hepatic encephalopathy: can my patient drive? J Clin Gastroenterol. 2017;51(2):118-26.

13. Bajaj JS, Hafeezullah M, Hoffmann RG, Saeian K. Minimal hepatic encephalopathy: a vehicle for accidents and traffic violations. Am J Gastroenterol. 2007;102(9):1903-9.

14. Bajaj JS, Saeian K, Hafeezullah M, Hoffmann RG, Hammeke TA. Patients with minimal hepatic encephalopathy have poor insight into their driving skills. Clin Gastroenterol Hepatol. 2008;6(10):1135-9.

15. Lauridsen MM, Thacker LR, White MB, Unser A, Sterling RK, Stravitz RT, Matherly S, Puri P, Sanyal AJ, Gavis EA, et al. In patients with cirrhosis, driving simulator performance is associated with real-life driving. Clin Gastroenterol Hepatol. 2016;14(5):747-52.

16. Watanabe A, Tuchida T, Yata Y, Kuwabara Y. Evaluation of neuropsychological function in patients with liver cirrhosis with special reference to their driving ability. Metab Brain Dis. 1995;10(3):239-48.

17. Wein C, Koch H, Popp B, Oehler G, Schauder P. Minimal hepatic encephalopathy impairs fitness to drive. Hepatology. 2004;39(3):739-45.

18. Roman E, Cordoba J, Torrens M, Torras X, Villanueva C, Vargas V, Guarner C, Soriano G. Minimal hepatic encephalopathy is associated with falls. Am J Gastroenterol. 2011;106(3):476-82.

19. Soriano G, Roman E, Cordoba J, Torrens M, Poca M, Torras X, Villanueva C, Gich IJ, Vargas V. Guarner C. Cognitive dysfunction in cirrhosis is associated with falls: a prospective study. Hepatology. 2012;55(6):1922-30

20. Ortiz M, Cordoba J, Jacas C, Flavia M, Esteban R, Guardia J. Neuropsychological abnormalities in cirrhosis include learning impairment. J Hepatol. 2006:44(1):104-10.

21. Weissenborn K. The clinical relevance of minimal hepatic encephalopathy-a critical look. Dig Dis. 2015b;33(4):555-61.

22. Ampuero J, Simón M, Montoliú C, Jover R, Serra MÁ, Córdoba J, RomeroGómez M. Minimal hepatic encephalopathy and critical flicker frequency are associated with survival of patients with cirrhosis. Gastroenterology. 2015;49(6):1483-9.

23. Lockwood AH, McDonald JM, Reiman RE, Gelbard AS, Laughlin JS, Duffy $T E$, Plum F. The dynamics of ammonia metabolism in man. Effects of liver disease and hyperammonemia. J Clin Invest. 1979;63(3):449-60.

24. Holecek M. Evidence of a vicious cycle in glutamine synthesis and breakdown in pathogenesis of hepatic encephalopathy-therapeutic perspectives. Metab Brain Dis. 2014;29(1):9-17.

25. Dam G, Ott P, Aagaard NK, Vilstrup H. Branched-chain amino acids and muscle ammonia detoxification in cirrhosis. Metab Brain Dis. 2013;28(2):217-20.

26. Dasarathy S, Merli M. Sarcopenia from mechanism to diagnosis and treatment in liver disease. J Hepatol. 2016;65(6):1232-44.

27. Qureshi MO, Khokhar N, Shafaat F. Ammonia levels and the severity of hepatic encephalopathy. J Coll Physicians Surg Pak. 2014;24(3):160-3.

28. Qiu J, Thapaliya S, Runkana A, Yang Y, Tsien C, Mohan ML, Narayanan A, Eghtesad B, Mozdziak PE, McDonald C, et al. Hyperammonemia in cirrhosis induces transcriptional regulation of myostatin by an NF-KB-mediated mechanism. Proc Natl Acad Sci USA. 2013;110(45):18162-7.

29. Hamaguchi Y, Kaido T, Okumura S, Fujimoto Y, Ogawa K, Mori A, Hammad A, Tamai Y, Inagaki N, Uemoto S. Impact of quality as well as quantity of skeletal muscle on outcomes after liver transplantation. Liver Transpl. 2014:20(11):1413-9.
30. Higashi T, Hayashi H, Taki K, Sakamoto K, Kuroki H, Nitta H, Hashimoto D, Chikamoto A, Beppu T, Baba H. Sarcopenia, but not visceral fat amount, is a risk factor of postoperative complications after major hepatectomy. Int J Clin Oncol. 2016;21(2):310-9.

31. Kaido T, Ogawa K, Fujimoto Y, Ogura Y, Hata K, Ito T, Tomiyama K, Yagi S, Mori A, Uemoto S. Impact of sarcopenia on survival in patients undergoing living donor liver transplantation. Am J Transplant. 2013;13(6):1549-56

32. Harimoto N, Yoshizumi T, Shimokawa M, Sakata K, Kimura K, Itoh S, Ikegami T, Ikeda T, Shirabe K, Maehara Y. Sarcopenia is a poor prognostic factor following hepatic resection in patients aged 70 years and older with hepatocellular carcinoma. Hepatolo Res. 2016;46(12):1247-55.

33. Iritani S, Imai K, Takai K, Hanai T, Ideta T, Miyazaki T, Suetsugu A, Shiraki M, Shimizu M, Moriwaki H. Skeletal muscle depletion is an independent prognostic factor for hepatocellular carcinoma. J Gastroenterol. 2015;50(3):323-32.

34. Hanai T, Shiraki M, Nishimura K, Ohnishi S, Imai K, Suetsugu A, Takai K, Shimizu M, Moriwaki H. Sarcopenia impairs prognosis of patients with liver cirrhosis. Nutrition. 2015;31(1):193-9.

35. Hayashi F, Matsumoto Y, Momoki C, Yuikawa M, Okada G, Hamakawa E, Kawamura E, Hagihara A, Toyama M, Fujii H, et al. Physical inactivity and insufficient dietary intake are associated with the frequency of sarcopenia in patients with compensated viral liver cirrhosis. Hepatol Res. 2013:43(12):1264-75.

36. Hanai T, Shiraki M, Watanabe S, Kochi T, Imai K, Suetsugu A, Takai K, Moriwaki H, Shimizu M. Sarcopenia predicts minimal hepatic encephalopathy in patients with liver cirrhosis. Hepatol Res. 2017;47(13):1359-67.

37. Merli M, Giusto M, Lucidi C, Giannelli V, Pentassuglio I, Di Gregorio V, Lattanzi B, Riggio O. Muscle depletion increases the risk of overt and minimal hepatic encephalopathy: results of a prospective study. Metab Brain Dis. 2013:28(2):281-4.

38. Lucero C, Verna EC. The Role of Sarcopenia and Frailty in Hepatic Encephalopathy Management. Clin Liver Dis. 2015;19(3):507-28.

39. Lattanzi B, D'Ambrosio D, Merli M. Hepatic encephalopathy and sarcopenia: two faces of the same metabolic alteration. J Clin Exp Hepatol. 2019;9(1):125-30.

40. Cai XJ, Wang L, Hu CM. Efficacy of different drugs in the treatment of minimal hepatic encephalopathy: A network meta-analysis involving 826 patients based on 10 randomized controlled trials. J Cell Biochem. 2018;119(10):8336-45.

41. Cao Q, Yu CB, Yang SG, Cao HC, Chen P, Deng M, Li LJ. Effect of probiotic treatment on cirrhotic patients with minimal hepatic encephalopathy: a meta-analysis. Hepatobiliary Pancreat Dis Int. 2018;17(1):9-16.

42. Dhiman RK, Thumburu KK, Verma N, Chopra M, Rathi S, Dutta U, Singal AK, Taneja S, Duseja A, Singh M. Comparative efficacy of treatment options for minimal hepatic encephalopathy: a systematic review and network meta-analysis. Clin Gastroenterol Hepatol. 2020;18(4):800-12.

43. Goyal O, Sidhu SS, Kishore H. Minimal hepatic encephalopathy in cirrhosis- how long to treat? Ann Hepatol. 2017;16(1):115-22.

44. Ridola L, Cardinale V, Riggio O. The burden of minimal hepatic encephalopathy: from diagnosis to therapeutic strategies. Ann Gastroenterol. 2018;31(2):151-64.

45. Duarte-Rojo A, Allampati S, Thacker LR, Flud CR, Patidar KR, White MB, Klair JS, Heuman DM, Wade JB, Gavis EA, et al. Diagnosis of covert hepatic encephalopathy: a multi-center study testing the utility of single versus combined testing. Metab Brain Dis. 2019;34(1):289-95.

\section{Publisher's Note}

Springer Nature remains neutral with regard to jurisdictional claims in published maps and institutional affiliations. 